\title{
PENGARUH LATIHAN SMALL SIDED GAME TERHADAP AKURASI PASSING PADA SISWA EKSTRAKULIKULER FUTSAL SMP NEGERI 1 MUARO JAMBI
}

\author{
Ahmad Muzaffar ${ }^{1}$, Adhe Saputra ${ }^{1}$ \\ ${ }^{1}$ Fakultas Ilmu Keolahragaan, Universitas Jambi, Jambi Indonesia \\ Correspondence Author : Ahmad Muzaffar muzaffar.fkip@unja.ac.id,
}

\section{ARTICLE INFO \\ Article History: \\ Received : August 20, 2019 \\ Revised form : August 20, 2019 \\ Accepted September 10, 2019 \\ Published online : September 11, 2019}

\section{Kata Kunci: \\ kata kunci 1; Small sided- games training \\ kata kunci 2; Passing accuracy kata kunci 3; Futsal}

\section{Keywords:}

keyword 1; latihan small sided game

keyword 2; Akurasi passing

keyword 3 ; Futsal
Small sided-games training is a small-scale field, an appropriate situation developed for young players, so they can learn and develop. Small sided games training is also one of the methods of soccer training using smaller fields with fewer players. This training method is a fairly effective exercise in physical improvement, techniques and tactics Passing is to feed the ball or pass the ball to a friend, while passing determination is the ability to set goals / pass the ball according to the goal or target. This research is an experimental research conducted with the aim to find out whether or not there is a result of something done on the sample to be studied. The research began with a pretest and ended with a posttest. The number of samples in this study amounted to 20 people. The training given was done during 16 meetings. This research was tested using a statistical analysis of the hipotsis test ( $t$ test). Based on data analysis, it can be concluded that the small sided games exercise gives a significant effect on the accuracy of passing on extracurricular students at SMP Negeri 1 Muaro Jambi, proven in the pre-test and post-test assessments with an average pre-test $=505$ and post-test $=7.65$, with the increment difference of 7.65. This can be seen by the $\mathrm{T}$ test that is Tcount $=$ $3.492787>$ Ttable $=1.72913$. Based on the results of research and calculations from the data and discussions that have been carried out, this research proves that there is an influence of small sided games training on the passing accuracy of extracurricular students at Muaro Jambi State Junior High School. 


\section{PENDAHULUAN}

Pendidikan adalah aspek yang sangat penting dalam kehidupan (Wibowo \& Sadikin, 2019) salah satu cabang ilmu pendidikan adalah pendidikan olahraga. Olahraga merupakan salah satu cara untuk menjaga agar kebugaran jasmani tetap berada dalam kondisi yang baik. Sering terlihat pria maupun wanita, tua atau muda melakukan latihan-latihan olahraga, baik di lapangan maupun di jalan. Semua ini mereka lakukan agar kesehatan dan kebugaran jasmani tetap baik yang digunakan sebagai dasar penting untuk hidup bahagia dan bermanfaat. Sucipto, dkk. (2000: 7) futsal merupakan permainan beregu, masing- masing regu terdiri dari lima pemain, dan salah satunya penjaga gawang. Permainan ini hampir seluruhnya dimainkan dengan menggunakan tungkai kecuali penjaga gawang yang diperbolehkan menggunakan lengannya didaerah tendangan hukumannya. Dalam perkembangannya permainan ini dapat dimainkan di luar lapangan (outdoor) dan di dalam ruangan tertutup (indoor). Futsal berkembang dengan pesat di kalangan masyarakat, karena permainan ini dapat dimainkan oleh laki-laki dan perempuan, anak-anak, dewasa, dan orang tua.

Futsal yang ada di Indonesia sejauh ini sangat berkembang dengan pesat, pada tahun 2010 Indonesia bisa menyelenggarakan futsal se-Asia di Jakarta. Pada saat itu, lahirlah tim nasional Indonesia yang pertama kali, seiring dengan perkembangan jaman dan perkembangan olahraga. Olahraga futsal dapat diterima oleh masyarakat secara luas yang ada di seluruh Indonesia. Bahkan banyak berdiri komunitas futsal atau klub futsal, selain itu banyak diselenggarakan pertandingan futsal. Dibandingkan dengan cabang olahraga permainan lainnya, futsal cukup populer dan tidak kalah dengan permainan sepakbola. Permainan futsal membentuk seorang pemain agar selalu siap menerima dan mengumpan bola dengan cepat dalam tekanan lawan. Dengan bermain futsal, pemain bisa mengembangkan kemampuannya dengan baik.

Permainan ini juga memberikan manfaat bagi sistem ketahanan tubuh karena nyaris sepanjang permainan, seorang pemain akan berlari ke segala penjuru lapangan, nyaris tanpa henti. Menurut Andri Irawan (2009: 22), teknik- teknik dasar dalam bermain futsal ada beberapa macam, seperti receiving (menerima bola), shooting (menendang bola ke gawang), passing (mengumpan), chipping (mengumpan lambung), heading (menyundul bola), dan dribbling (menggiring bola). Terdapat teknik dan gerakan yang bisa dilakukan pemain di dalam lapangan. Sehingga di dalam lapangan terdapat berbagai kombinasi teknik dan gerakan yang dimiliki setiap pemain sangatlah mendukung dalam penguasaan bola untuk mencapai sebuah kemenangan.

Pembelajaran ekstrakurikuler olahraga futsal (ketepatan passing) di SMP Negeri 1 Muaro Jambi belum menunjukkan hasil yang maksimal, contohnya seperti saat mengikuti turnamen antar SMP Se-Provinsi 
Jambi para pemain ini masih melakukan kesalahan passing sehingga bolanya melenceng tidak tepat pada sasaran, melambung, atau mengenai pemain bertahan dari lawan sehingga terjadi serangan balik yang mengakibatkan tim mengalami kekalahan. Pada kenyataannya para pemain sering melakukan kesalahan mendasar ketika melakukan passing, sehingga merugikan tim ketika bertanding. Ketepatan passing perlu dikembangkan atau ditingkatkan. Adanya masalah di atas dibutuhkan sebuah cara belajar baik dan tepat yaitu dengan sebuah pendekatan bermain. Pada dasarnya siswa usia SMP senang melakukan permainan karena bersifat menyenangkan, mudah, menarik, sederhana, dan dapat dilakukan secara sukarela. Dalam penelitian ini permainan small sided-games dianggap tepat untuk meningkatkan ketepatan passing saat dalam situasi pertandingan.

Latihan Small sided-games merupakan suatu latihan yang berkembang dengan menyajikan situasi permainan yang membuat pemain mendapatkan penguasaan aspek teknik, taktik, dan fisik sekaligus. Latihan Small sided-games lebih banyak menerapkan secara langsung latihan teknik, taktik, dan fisik dalam sebuah permainan (game) yang berarti pemain dituntut untuk menghadapi situasi tekanan seolah-olah dalam situasi permainan sesungguhnya. Bentuk latihan Small sided-games juga bisa dijadikan model latihan alternatif bagi para siswa agar bentuk latihan yang diberikan oleh pelatih tidak monoton dan menjenuhkan bagi siswa. Sejauh ini pembelajaran ekstrakurikuler olahraga futsal di SMP Negeri 1 Muaro Jambi belum menunjukkan hasil yang maksimal, sehingga perlu dikembangkan atau ditingkatkan. Dari permasalahan di atas penulis akan meneliti "pengaruh latihan small sided game terhadap akurasi passing pada siswa ekstrakulikuler futsal SMP Negeri 1 Muaro Jambi”.

\section{METODE}

Penelitian ini adalah eksperiman one groups pretest-postest design yaitu eksperimen yang dilakukan hanya pada satu kelompok saja tanpa kelompok pembanding. Menurut Suharsimi Arikumto (2002: 272) penelitian eksperiman merupakan penelitian yang dimaksudkan untuk mengetahui ada tidaknya akibat dari suatu yang dikenakan pada subyek selidik. Kelompok dalam penelitian ini diberi prestest, treatment, dan posttest. Penelitian ini dilakukan dengan memberikan tes awal (pretest) lebih dahulu, kemudian diberi perlakuan dengan permainan small sided-games (treatment), setelah itu diberi tes akhir (posttest). Adapun desain penelitian dituangkan dalam bentuk gambar sebagai berikut:

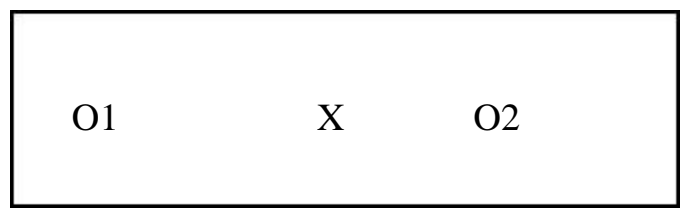

Gambar 3.1 Desain Penelitian

Keterangan:

O1, Pretest : Test awal dengan passing ke gawang dan harus sampai ke teman pasanganya sebanyak 10 kali dilakukan sebelum subyek mendapatkan perlakuan (treatment).

$\mathrm{X} \quad$ : Perlakuan (treatment) menggunakan permainan small sided- games.

O2, Postes : Tes akhir dengan passing dengan daerah sasaran sebanyak 10 kali, dilakukan setelah subyek mendapat perlakuan eksperimen. 
Variabel bebas dalam penelitian ini adalah latiahan small sided-games. Latihan small sided-games merupakan program latihan yang dimainkan di lapangan yang lebih kecil dari lapangan sebenarnya. Variabel terikat dalam penelitian ini adalah akurasi passing. Akurasi passing adalah kemampuan dalam menempatkan / mengoper bola ke sasaran sesuai dengan tujuan dalam penelitian ini. Passing diukur dengan tes mengoperkan bola dengan menghitung jumlah tendangan yang masuk sah dari sepuluh kali tendangan

Menurut Sugiyono (2009: 133) instrumen penelitian digunakan untuk mengukur nilai variabel yang diteliti. Syarat tes yang baik adalah memiliki validitas dan reliabilitas. Instrumen yang digunakan dalam penelitian ini yaitu tes mengoper bola yang memiliki validitas dan reliabilitas. Reliabilitas instrumen ini sebesar 0,879 dan validitas sebesar 0,812. Alat yang digunakan untuk mengukur yaitu meteran. Testi berpasangan dan berhadapan masing-masing testi bergantian melakukan passing dengan awalan bola diam dan di passing melewati di dalam gawang (sasaran) yang telah di siapkan. Jarak dari testi ke sasaran adalah 9 Meter dan jarak testi satu ke yang testi kedua adalah $18 \mathrm{M}$, pelaksanaan dihitung berhasil apabila masingmasing testi passing masuk ke dalam sasaran yang telah dibuat dan sampai ke teman yang di hadapannya.

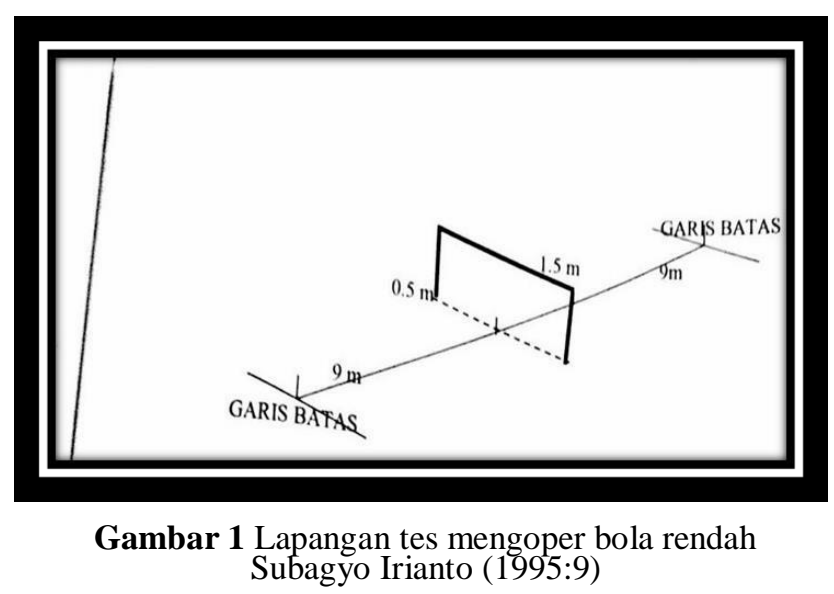

\section{HASIL}

\section{Deskripsi Data}

Deskripsi data adalah hasil dari tes passing bola pada siswa ekstrakulikuler futsal SMP N 1 Muaro Jambi yang berjumlah 20 orang.

Tabel 1. Distribusi tes awal

\begin{tabular}{|c|c|c|c|c|c|c|c|}
\hline & & $\mathrm{N}$ & $X$ & SD & $\mathrm{N}$ & Nilai min & Nilai max \\
\hline Tes Awal & 2 & 0 & 5.05 & 1.733 & & 3 & 7 \\
\hline
\end{tabular}

Berdasarkan Penyebaran data dari hasil pri test dengan jumlah sampel 20 orang didapat nilai minimum 3 dan nilai maksimum 7 dengan nilai rata-rata 5.05 dan standar deviasi 1.733

Tabel 2. Frekuensi tes awal

\begin{tabular}{ccc}
\hline No & $\begin{array}{c}\text { Tes awal } \\
\text { Kelincahan (detik) }\end{array}$ & Frekuensi \\
\cline { 3 - 3 } & $1-3$ & Fa \\
\hline 1 & $4-5$ & 3 \\
\hline 2 & $6-7$ & 9 \\
\hline 3 & Jumlah & $\underline{20}$ \\
\hline & &
\end{tabular}


Tes awal latihan ini tidak melakukan latihan Small sided-games, sehingga dalam tes awal ini murni tidak ada perlakuan terhadap pemain siswa ekstrakurikuler SMP Negeri 1 Muaro Jambi. Pada tes awal ini didapatkan hasil passing bola.

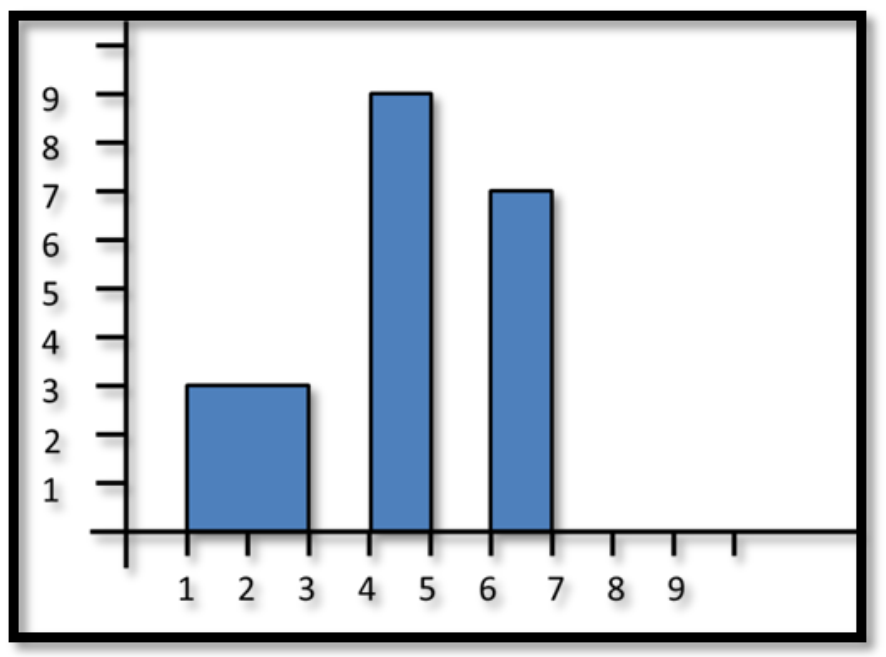

Gambar 2. Diagram Batang Tes Awal

\section{Tes Akhir}

Tabel 3. Distribusi tes akhir

\begin{tabular}{lrrrcc}
\hline Hasil Test & $\mathrm{N}$ & $\mathrm{X}$ & $\mathrm{SD}$ & Nilai min & Nilai max \\
\hline Tes Akhir & 20 & 7.65 & 2004 & 4 & 10 \\
\hline
\end{tabular}

Berdasarkan Penyebaran data dari hasil pri test dengan jumlah sampel 20 orang didapat nilai minimum 4 dan nilai maksimum 10 dengan nilai rata-rata 7.65 dan standar deviasi 2.004.

Tabel 4. Frekuensi tes akhir

\begin{tabular}{lcc}
\hline & Tes akhir & Frekuensi \\
NO & kelincahan (detik) & \\
\cline { 3 - 3 } & & Fa \\
\hline 1 & $0-4$ & 0 \\
\hline 2 & $5-6$ & 7 \\
\hline 3 & $7-8$ & 11 \\
\hline 4 & $9-10$ & 5 \\
\hline & Jumlah & 20 \\
\hline
\end{tabular}

Tes akhir dalam penelitian ini merupakan yang telah dilakukan perlakuan sebannyak 16 kali pada siswa ektrakurikuler SMP Negeri 1 Muaro Jambi, latihan yang diberikan merupakan latihan Small sidedgames. Pada tes akhir ini didapatkan hasil dari passing bola siswa ekstrakurikuler SMP Negeri 1 Muaro Jambi dari 20 orang. 


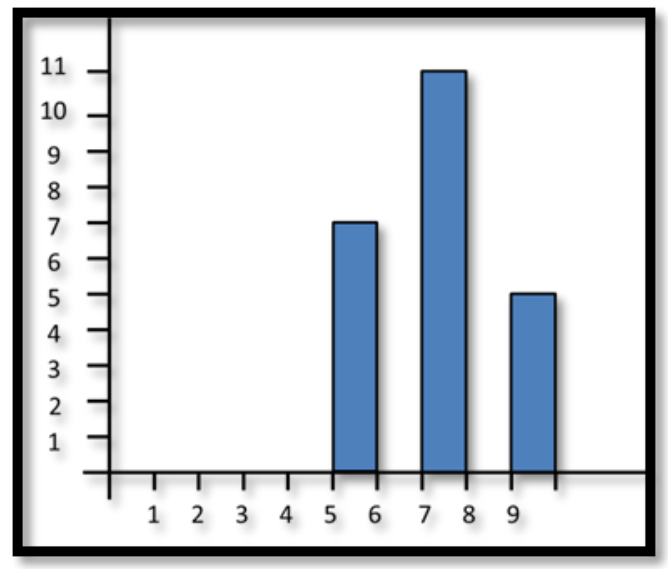

Gambar 3. Diagram Batang Tes Akhir

Maka dapat disumpulkan dari hasil frekuensi antara tes awal dan tes akhir terdapat peningkatan yang signifikan. Jika dilihat dari rata-rata tes awal 505 dan rata-rata tes akhir 7.65 dari rata-rata ini terdapat peningkatan setelah dilakukan latihan Small sided-games.

\section{Hasil Penelitian}

Setelah dilakukannya penelitian yang berjudul pengaruh latihan Small sided-games yang dilakukan selama 16 kali pertemuan mendapatkan hasil penelitian dimana diman data yang diperoleh diambil menggunkan pre test dan post test dengan menggunakan instrument $T$ test. Setelah dilakukan pre test dan post test pada kelompok sampel dilakukan perhitungan rata-rata(X), simpang baku $(\mathrm{S})$, dan varians $\left(\mathrm{S}^{2}\right)$. Adapun hasil perhitungan data tersebut dapat dilihat pada tabel berikut:

Tabel 5. Hasil Pengukuran PreTtes Dan Post Test

\begin{tabular}{lcc}
\hline \multicolumn{1}{c}{$\mathrm{N}=20$} & Pre test & Post test \\
\hline Jumlah & 103 & 153 \\
\hline Rata-rata & 5.05 & 7.65 \\
\hline
\end{tabular}

Tabel 6. Perhitungan Rata-Rata Standar Deviasi Dan Varians

\begin{tabular}{cccccc} 
Tes & $\mathrm{Xi}$ & $\mathrm{N}$ & $\mathrm{X}$ & $\mathrm{S}$ & $\mathrm{S}^{2}$ \\
\hline Pre Test & 03 & 20 & 505 & 0.73 & 0.56 \\
\hline Post Test & 153 & 20 & 7.65 & 150 & 2.24 \\
\hline
\end{tabular}

\section{Uji Normalitas}

Uji normalitas dilakukan dengan uji lilifors. Hasil perhitungan dari tes awal Lhitung $=0.153$ Ltabel $=0.190$ dan tes akhir di peroleh Lhitung=0.186 Ltabel $=\mathrm{Lt}=0.190$. Dikarenakan Lhitung $<$ Ltabel, dapat disimpulkan bahwa kedua kelompok sampel berdistribusi normal. 


\section{Uji Homogenitas}

Setelah dilakukan perhitungan statistik Fhitung=0.00350 dan $\mathrm{F}$ tabel $=2.17$ dikarenakan Fhitung $<$ Ftabel maka, data dari kedua kelompok sampel homogen pada taraf kepercayaan 95\%.

\section{Uji Hipotesis}

Hasil perhitungan statistik data kelompok sampel diketahui bahwa data tersebut berdistribusi normal dan mempunyai varians yang homogen. Kemudian diajukan lagi dengan uji hipotesi. Uji Hipotesis dilakukan dengan menggunakan Uji T dimana hal ini untuk mengetahui apakah hipotesis diterima atau ditolak. Adapun hasil perhitungan yang diperoleh yaitu Thitung=3.492787 dan Ttabel=1.72913 pada taraf kepercayaan $95 \%$ atau $\alpha=0.05$ dan derajat kebebasan $(\mathrm{dk})=(20-1)=19$. Hal ini bearti Thitung $>$ Ttabel, maka dalam analisis data di peroleh $3.492787>1.72913$.

Dari hasil tersebut maka, hipotesis yang menyatakan "terdpat pengaruh latihan Small sided-games pada siswa ekstrakurikuler SMP Negeri 1 Muaro Jambi”, diterima. Artinya dapat disimpulkan bahwa Thitung > Ttabel, Ho diterima dengan taraf kepercayaan $95 \%$.

\section{Pembahasan}

Berdasarkan latar belakang masalah yang telah di jelaskan bahwa siswa ekstrakulikuler SMP Negeri 1 Muaro Jambi banyak mengalami kesalahan saat passing bola, contohnya saat mengikuti turnamen antar SMP Se Provinsi Jambi para pemain ini masih melakukan kesalahan saat passing sehingga bola melenceng, melambung atau mengenai permainan lawan sehingga mereka mengalamin kekalahan.

Small sided-games merupakan salah satu metode latihan yang sedang berkembang saat ini. Small sided-games adalah metode latihan dalam sepakbola menggunakan lapangan yang kecil dengan lapangan yang kecil.

Hasil Perhitungan uji normalitas dilakukan dengan uji lilifors. Hasil perhitungan dari tes awal Lhitung=0.153 Ltabel $=0.90$ dan tes akhir di peroleh Lhitung=0.1864 Ltabel= Lt=0.190 Dikarenakan Lhitung $<$ Ltabel, dapat disimpulkan bahwa kedua kelompok sampel berdistribusi normal. Setelah dilakukan perhitungan statistik Fhitung=0.003507 dan $\mathrm{F}$ tabel $=2.17$ dikarenakan Fhitung $<$ Ftabel maka, data dari kedua kelompok sampel homogen pada taraf kepercayaan 95\%. Setelah dilakukan penelitian kemudian diperoleh hasil pre test dan post test, dimana nilai rata-rata adalah 5.05 dan 7.65. Dari hasil data dan uji hipotesis maka, dapat diketahui adanya pengaruh latihan Small sided-games terhadap akurasi passing siswa ekstrakurikuler futsal SMP Negeri 1 Muaro Jambi. Hal ini dapat dilihat dari perhitungan statistik dengan uji $\mathrm{T}$ yaitu Thitung lebih besar dari Ttabel yaitu $3.492787>1.72913$, jadi terbukti ada pengaruh latihan Small sided-games terhadap akurasi passing siswa ekstrakurikuler futsal SMP Negeri 10 Muaro Jambi.

Peningkatan akurasi passing terjadi karena telah diberikannya latihan Small sided-games.Latihan ini sangat berguna untuk menignkatkan prstasi dalam bidang sepakbola, ini dikarenakan latihan yang terprogram dan terarah dengan menggunakan metode Small sided-games.

\section{KESIMPULAN}

Berdasarkan analisis data, dapat disimpulkan bahwa latihan small sided games memberi pengaruh yang segnifikan terhadap akurasi passing pada siswa ekstrakurikuler SMP Negeri 1 Muaro Jambi dibuktikan 
pada penilaian pre test dan post test dengan nilai rata-rata pre test $=505$ dan post test $=7.65$, dengan selisih pengingkatan sebesar 7.65. Hal ini dapat dilihat dengan uji T yaitu Thitung=3.492787 > Ttabel=1.72913 Jadi, penelitian ini membuktikan terdapat ada pengaruh latihan small sided games terhadap akurasi passing siswa ekstrakulikuler SMP Negeri 1 Muaro Jambi.

\section{DAFTAR PUSTAKA}

Ali Maksum. (2012). Metodologi Penelitian Dalam Olahraga. Surabaya: Unesa University Press Adhe dan hendri. (2015). Tehnik Dasar \& Peraturan Permainan Futsal Jambi: Salim Media Indonesia Andri Irawan. (2005). Penyusun Instrumen Tes Ketrampilan Teknik Futsal Pada Mahasiswa DKI Jakarta.

Skripsi. Jakarta: FIK UNJ.

Andri Irawan. (2009). Teknik Dasar Modern Futsal. Jakarta: Pena

Andri Setyawan. (2010). Teknik Permainan Futsal. Jakarta: Sunda Kelapa Pustaka

Asmar Jaya. (2008). Futsal Gaya Hidup, Peraturan, dan Tips-Tips Permainan. Yogyakarta. Pustaka Timur Athanius Fikas Setiawan. (2009). Pengaruh Modifikasi Latihan Small Sided Games terhadap Peningkatan

Daya Tahan Aerobik dan Anaerobik Siswa Sekolah Sepakbola Matra Usia 11-12 tahun. Skripsi. Yogyakarta: FIK UNY.

http://pengertianfutsalteknikmaindanskill.blogspot.co.id/2016/09/a.html (di akses 02 januari2019

Justinus Lhaksana. (2011). Taktik dan Strategi Futsal Modern. Jakarta: Be Champion (2004). Indonesia Berpotensi Untuk Futsal. Jakarta Sport Cast. Edsi 14.

Muhammad Asriady Mulyono. (2014). Buku Pintar Panduan Futsal. JakartaLaskar Aksara

Murhananto. (2006). Dasar-dasar Permaianan Futsal (Sesuai Dengan Peraturan Futsal FIFA.) Jakarta: PT. Kawan Pustaka.

Roeslan Hatta (2006). Peraturan Permainan Futsal. Jakarta: Difamata Sport E.O.

Rohmad Nur Ichsan. (2013). Pengaruh Latihan Small sided-games TerhadapAkurasi Passing Siswa Yang

Mengikuti Ekstrakurikuler Sepakbola Di SMP Negri 1 Nglipar Gunungkidul. Skripsi. Yogyakarta:

FIK UNY.

Saryono. (2006). Futsal Sebagai Salah Satu Permainan Alternatif Untuk Pembelajaran Sepakbola Dalam

Pendidikan Jasmani. Yogyakarta: Universitas Negri Yogyakarta

Sukadiyanto. (2011). Pengantar Teori dan Metodologi Melatih Fisik. Bandung: CV Lubuk Agung

Suharsimi Arikunto. (2006). Prosedur Penelitian. Jakarta: PT. Rineke Cipta. (2010). Prosedur Penelitian.

Jakarta: PT. Rineke Cipta..

Tony Charles. (2012). 101 Sesi Latihan Sepakbola Untuk Pemain Muda. Jakarta. Indeks.

Wibowo, Y. G., \& Sadikin, A. (2019). Biology in 21 st -Century: Transformation in Biology Science and Education for Supporting Sustainable Development Goals. Jurnal Pendidikan Biologi Indonesia, 5(2), 285-296 